\title{
PERAN DUNIA PENDIDIKAN DAERAH KABUPATEN KARIMUN \\ DALAM MENINGKATKAN KUALITAS SUMBER DAYA MANUSIA GUNA MENCIPTAKAN DAYA SAING INVESTASI DAN LAPANGAN KERJA DALAM RANGKA PEMBANGUNAN NASIONAL (DAERAH PERBATASAN)
}

\begin{abstract}
Nurdin Basirun*
Abstract: Local government Kabupaten Karimun contend thats improvement of human resource quality (SDM) is priority of area development to competitive ability, investment and employment in order to national development. Resources Development that with quality must cover development competitive SDM, with character, development as the citizen Indonesia that can esteem religion and cultural "kebhinekaan", human being, fatherland love, democratic and fair. To develop SDM are referred as, become duty of educator energy to be able to their patterned thinking fox. Expected educator is educator that have energy mental combatant that can form student that independence, think, personality (be, trusted, honesty), work ethics, clever and skillful according to concept of archipelagic country development for example grow maritime knowledge for society and government in order to development Indonesia oceanic orientation; and improved human resource capacities that with vision of oceanic pass by development of oceanic science and technology.
\end{abstract}

Keywords : Role of Area Education, Quality SDM, Competitive Ability.

\section{PENDAHULUAN}

Secara geografis dan topografis letak Kabupaten Karimun sangat strategis terlihat dari peta. Jumlah penduduk Indonesia pada saat sekarang ini termasuk terbesar di dunia +266 juta jiwa dan Kabupaten Karimun saat ini sudah mencapai 272.000 jiwa.

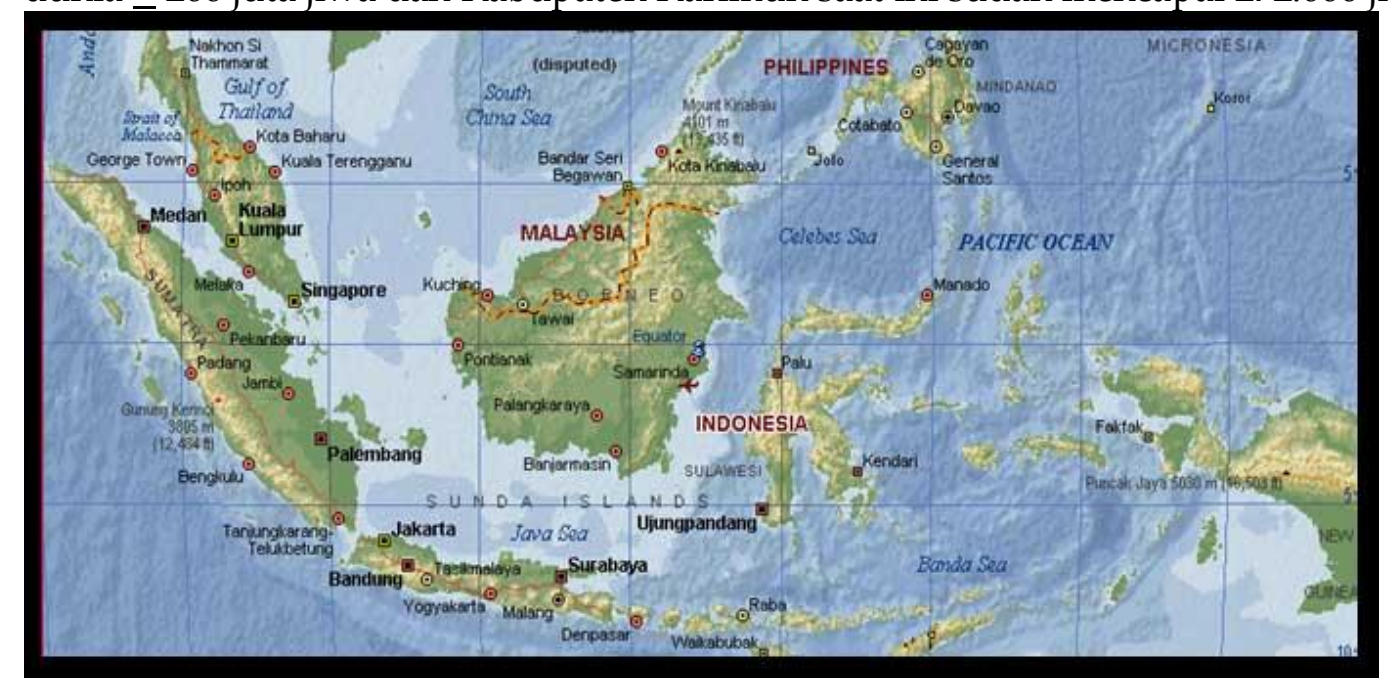

PETA KARIMUN

\footnotetext{
* Bupati Kabupaten Karimun
} 


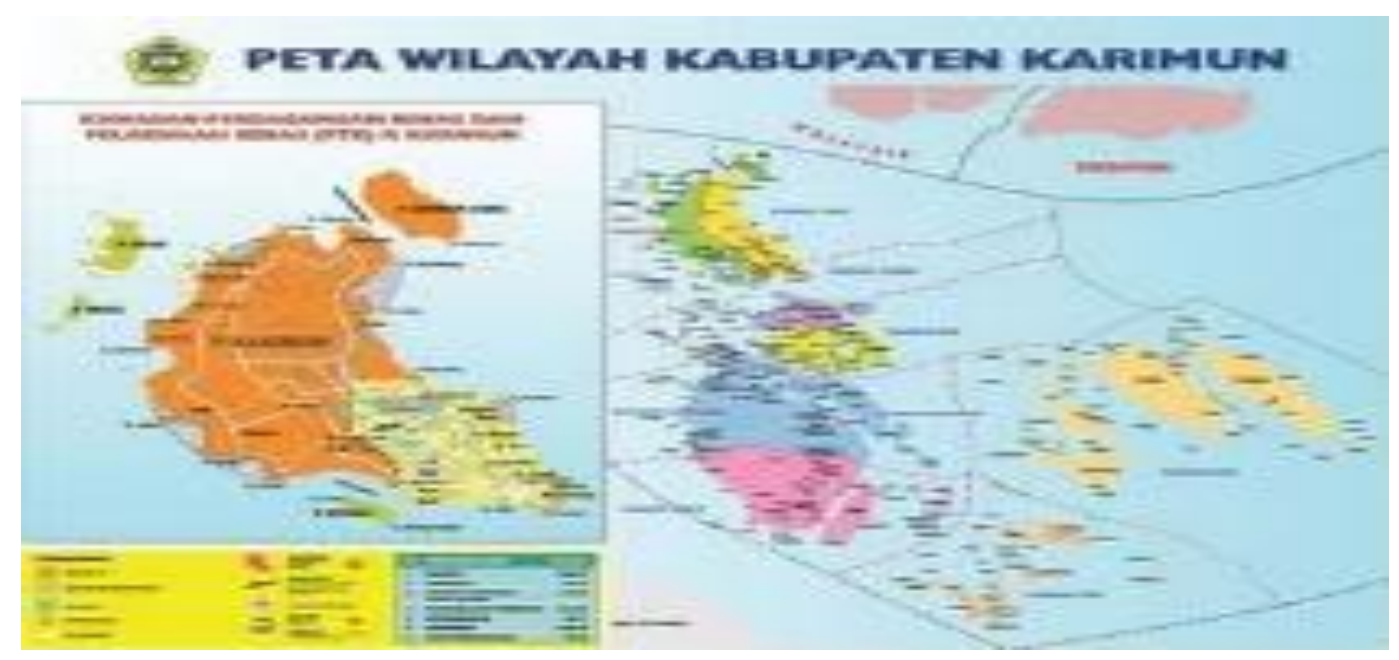

Visi Pembangunan Karimun

Dalam paradigma pembangunan untuk mencapai suatu perubahan ke arah kemajuan maka, visi pembangunan Kabupaten Karimun adalah "Terwujudnya Kabupaten Karimun yang Maju, Mandiri, Berdaya Saing, Adil dan Berbudaya Berlandaskan Iman dan Taqwa 2025".

Step by step setiap langkah pembangunan terukur terarah dan tepat sasaran.

Motto Kabupaten Karimun

Sebagai motivator baik secara intrinsik maupun secara ekstrinsik maka konsep semangat kerja masyarakat Kabupaten Karimun adalah melaksanakan berbagai profesinya sebagai berikut:

1. Kerja amanah

2. Kerja keras

3. Kerja cerdas

Dalam mewujudkan nilai-nilai dan pembangunan maka, azam pembangunan Kabupaten Karimun ada 4 (empat):

1. Azam peningkatan iman dan taqwa.

2. Azam pembangunan ekonomi yang berdimensi kerakyatan.

3. Azam peningkatan kualitas sumber daya manusia.

4. Azam pengembangan seni dan budaya.

Misi Pembangunan Karimun

Penjabaran dari visi pembangunan Kabupaten Karimun maka dituangkan dalam bentuk misi:

1. Mengembangankan potensi pertanian, perikanan dan kelautan berbasis ekonomi kerakyatan dan mendorong pemerataan pembangunan di seluruh wilayah.

2. Meningkatkan pertumbuhan industri kecil, menangah dan besar serta koperasi dengan struktur industri yang kuat melalui keterkaitan antara sektor dan antara industri serta mewujudkan pusat perdagangan dan jasa modern dengan dukungan agro bisnis dan agro industri sehingga mampu menghasilkan produk yang memiliki daya saing yang kuat.

3. Mewujudkan masyarakat Kabupaten Karimun yang beriman dan bertakwa, berbudaya mempunyai etos kerja tinggi, berdisiplin, berkualitas, terampil cerdas dan jujur, berjiwa sosial dan bergotong royong, sehat dan sejahtera, mengusai sains dan teknologi sesuai dengan perkembangan zaman. 
4. Mewujudkan rasa aman dan damai, supremasi hukum dan HAM, demokrasi dan pemerintahan yang tertib, efektif dan efesien menuju terwujudnya good governance (ketata pemerintahan yang baik).

5. Mewujudkan pembangunan infrastruktur perkotaan dan pedesaan serta kawasan pesisir dan perbatasan sehingga terlaksana pertumbukan dan pemerataan pembangunan yang berkelanjutan.

Pembangunan nasional pada hakikatnya adalah upaya mewujudkan tujuan nasional bangsa Indonesia yang maju, mandiri, berkeadilan, berdasarkan iman dan taqwa kepada Tuhan yang Maha Kuasa, yang berlandaskan Pancasila dan UUD 1945. Sebagai negara yang ikut menandatangani Millenium Development Goals (MDGS) pada september 2000, maka Indonesia berkewajiban ikut serta dalam pembangunan ekonomi dan peningkatan kesejahteraan. Dengan diberlakukannya Undang-Undang no.32 tahun 2004 dan Undang-Undang no.33 tahun 2004, Pemerintah Daerah diberi kewenangan untuk mengatur dan mengurus sendiri urusan pemerintahan menurut asas otonomi dan tugas pembantuan.

Pemerintah daerah Kabupaten Karimun sudah menetapkan bahwa peningkatan kualitas sumber daya manusia merupakan prioritas pembangunan daerah guna daya saing, investasi dan lapangan kerja dalam rangka pembangunan nasional. Fenomena yang terjadi dalam menghadapi berbagai tantangan pembangunan khususnya tentang sumber daya manusia (SDM), permasalahan yang ada diantaranya sebagai berikut:

1. Sebagian besar angkatan kerja di Karimun belum memiliki daya saing yang tinggi.

2. Masih rendahnya tingkat pendapatan sebagian masyarakat.

3. Belum optimalnya akses masyarakat terhadap layanan pendidikan yang berkualitas.

4. Belum meratanya akses masyarakat terhadap layanan kesehatan yang berkualitas.

\section{PEMBAHASAN}

Ruang lingkup pembangunan pendidikan perlu dikembangkan karena ada kecenderungan untuk melihat pendidikan hanya sebagai pendidikan dalam sekolah dan diabaikan potensialitas yang lebih luas, hal ini tercermin, misalkan dalam kecenderungan masyarakat untuk mendapatkan gelar atau ijazah. Agar dapat mengembangkan potensial manusia harus memanfaatkan berbagai jaringan pendidikan karena ada beberapa alasan:

1. Perkembangan ilmu pengetahuan dan teknologi begitu cepat sehingga mengharuskan orang untuk belajar terus.

2. Dunia kerja atau properti semakin menyesuaikan diri dengan perkembangan ilmu pengetahuan dan teknologi, maka pengetahuan dan keterampilan harus terus ditingkatkan.

3. Sekolah tidak mungkin menyediakan SDM yang siap pakai, maka harus dilengkapi dengan pendidikan lainnya yang dapat dikerjakan dalam sekolah adalah menyiapkan SDM yang mampu beradaptasi dengan situasi baru dan dapat mengembangkan diri lebih lanjut.

Dalam pengembangan SDM baik secara kualitatif dan kuantitatif haruslah memperhatikan hal-hal sebahai berikut:

1. Membangun karakter bangsa.

Karakter dapat dikembangkan dan bahkan diturunkan secara genetik meskipun unsur lainnya ada, dan bisa juga karakter dapat dihasilkan dari proses pendidikan. 
Karakter dapat mengalami perkembangan atau perubahan. Pertanyaannya adalah apakah karakter nasional dapat dibentuk, jawabnya dapat.

2. Meskipun tidak mudah, misalnya suatu pendidikan karakter nasional yang diinspirasikan oleh nilai-nilai pendidikan akan menjadikan manusia berwatak, mampu menghargai perbedaan, manusiawi dan santun, mencintai tanah airnya, demokratis, adil dan solidaritas.

3. Banyak negara yang tidak menganut nilai-nilai seperti nilai yang terkandung dalam Pancasila tetapi memiliki SDM yang lebih unggul.

Apakah nilai-nilai Pancasila dapat memberi nilai tambah atau meningkatkan kualitas SDM Indonesia?

Jawabnya: harus dapat meskipun Pancasila bukan segala-galanya.

4. Pilar pengembangan SDM untuk menghadapi abad ke 21: (a) Learning to know (b) Learning to do, (c) Learning to live together, and (d) Learning to be.

Learning to know, yaitu antara lain; (1) Perkembangan ilmu pengetahuan dan teknologi sangat cepat, (2) SDM harus mampu mengembangan pengetahuan melalui berbagai instrumen pengetahuan, (3) masyarakat menuju learning society, knowledge society, dan (3) science based industries.

Learning to do, yaitu antara lain: (1) Kaitan teori dan praktek, (2) from skills to competition, (3) demoteralisasi kerja, dan (4) industri jasa.

Learning to live together, yaitu antara lain: (1) Belajar mengatasi konflik dan kekerasan, (2) belajar berkomunikasi, (3) berpartisipasi, dan (4) dialog.

Learning to be, yaitu antara lain: (1) Pengembangan diri yang utuh, (2) aktualisasi diri baik sebagai individu maupun sebagai makhluk social, (3) berkepribadian, (4) berkarakter, (5) berintegritas, dan (6) kebebasan yang dewasa.

Kaitan dengan implementasi nilai-nilai Pancasila, maka keempat pilar (Learning) tersebut dapat digambarkan dalam matrik:

\begin{tabular}{|l|l|l|}
\hline \hline No & Empat pilar & Nilai-nilai Pancasila \\
\hline 1. & Learning to know & Mencerdaskan kehidupan bangsa \\
2. & Learning to do & Kemanusiaan yang adil dan beradab \\
K. & Learning to live together & $\begin{array}{l}\text { Kebangsaan } \\
\text { Keadilan sosial }\end{array}$ \\
\hline 4. & Learning to be & $\begin{array}{l}\text { Sila Ketuhanan Yang Maha Esa } \\
\text { Kepribadian Indonesia } \\
\text { Berkarakter }\end{array}$ \\
\hline
\end{tabular}

Pengembangan sumber daya yang berkualitas harus mencakup pengembangan SDM yang berdaya saing, berkarakter, pengembangan sebagai warga negara Indonesia yang dapat menghargai kebhinekaan yang religius dan kultural, manusiawi, cinta tanah air, demokratis dan adil.

Paradigma Pembangunan yaitu melanjutkan paradigma baru pembangunan perbatasan. Dilihat dari letak di muka bumi, Indonesia bagian dari benua Asia yang tergabung dalam kelompok negara ASEAN, kondisi yang dihadapi adalah sebagai berikut:

1. Berbatasan dilaut dengan 10 negara dan di darat 3 negara. 
2. Beberapa persoalan perbatasan maritim belum terselesaikan, potensi konflik, kerawanan terhadap kedaulatan negara, kondisi keamanan di daerah perbatasan.

3. Selama 50 tahun terakhir sektor bahari menjadi terpinggirkan bersama dengan penduduk perbatasan.

4. Fakta menunjukkan kondisi sosial ekonomi dan pembangunan pada umumnya di daerah perbatasan sangat tertinggal.

5. Kondisi masyarakat perbatasan minim sarana kesehatan, pendidikan, transportasi, komunikasi, ekonomi dan rawan pelanggaran.

6. Kebijakan pemerintah belum mampu mewujudkan peningkatan infrastruktur.

7. Wilayah perbatasan memiliki peran sangat penting dan strategis yang merupakan batas kedaulatan negara atau mencerminkan halaman depan negara.

8. Perlu perhatian segenap komponen bangsa.

9. Permasalahan yang muncul akan berimplikasi terhadap keamanan negara.

Kebijakan baru yang harus diambil menjadikan kawasan perbatasan negara sebagai beranda terdepan sehingga pendekatan pembangunan pendidikan menjadi aspek pembangunan pertahanan serta memperhatikan lingkungan hidup dan dengan tetap memperhatikan aspek keamanan sebagaimana tersurat dan tersirat di dalam UU No.43 Tahun 2008 tentang Wilayah Negara dan Peraturan Presiden No.12 Tahun 2010 tentang Pembentukan Badan Nasional Pengelolaan Perbatasan (BNPP).

Tantangan khas dan pembangunan nasional saat ini:

1. Kondisi Indonesia dengan indeks daya saing yang memprihatinkan.

2. Tingkat koreksi, peredaran narkoba dan terorisme.

3. Kurang daya tarik investasi.

4. Proses reformasi yang belum rampung.

5. Tantangan khas demokratisasi.

6. Krisis pangan dunia dan krisis energy.

7. Global financial crisis.

Kualitas SDM berdaya saing global, yaitu: (1) SDM yang memiliki sikap dan kemampuan, (2) be trusted $\mathcal{E}$ honesty, (3) Resilence $\mathcal{E}$ strength, (4) Induktif, (5) Kreatif, (6) Produktif, dan (7) disiplin semangat kerja yang tinggi.

Salah seorang pakar ekonomi yang bernama Schumacher dengan bukunya "small is beautiful". Beliau penggagas pembangunan ekonomi bertahap menyatakan 3 (tiga) unsur SDM yang berkualitas: (1) Berpendidikan, (2) beretos kerja (disiplin), dan (3) berketerampilan berorganisasi.

Kondisi etos kerja saat ini, yaitu perlu kiranya kita mengintrospeksi diri (self concept) dan perlu menjawab beberapa pertanyaan:

Bagaimana kondisi etos kerja kita saat ini?

Beberapa persen anak-anak bangsa saat ini masih beretos kerja tinggi?

Pernahkah bangsa Indonesia memiliki etos kerja tinggi?.

Bangsa Indonesia pernah memiliki etos kerja tinggi. Melihat sejarah masa lalu pembangunan candi Borobudur adalah bukti kedahsyatan etos kerja nenek moyang kita. Hal yang lebih dahsyat adalah perjuangan fisik dan diplomatik merebut kemerdekaan pada masa revolusi, tanpa etos kerja yang luar biasa mustahil bagi Indonesia merebut kemerdekaan. Untuk mengetahui kondisi etos kerja dan beberapa persen anak-anak bangsa yang masih memiliki etos kerja tinggi yaitu: bekerja dengan tulus, kesungguhan dan paripurna seperti telah ditunjukkan oleh para pahlawan, untuk hal ini nampaknya perlu penelitian khusus. Walaupun tidak dipungkiri, cukup banyak anak-anak bangsa yang berprestasi dan telah mengharumkan nama bangsa Indonesia 
di dunia internasional. Sekalipun itu dapat menjadi sia-sia oleh berbagai predikat buruk Indonesia.

Schumacher yang dikenal sebagai penganjur strategi pembangunan ekonomi secara gradual, mengatakan kemiskinan dan ketertinggalan faktor-faktor material hanyalah merupakan penyebab skunder saja. Penyebab utamanya atau primer adalah: rendahnya pendidikan, keterampilan organisasi dan rendahnya disiplin.

Diumpamakan sebatang pohon, etos kerja merupakan akar, pendidikan dan pengetahuan merupakan batangnya, keterampilan organisasi merupakan dahan dan rantingnya. Langkah-langkah yang perlu dilakukan di dunia pendidikan:

1. Etos kerja harus disosialisasikan dan dikaitkan secara tegas dalam upaya peningkatan ilmu pengetahuan masyarakat, berilmu pengetahuan harus menjadi bagian integral dari visi sukses setiap anak bangsa, artinya belajar harus manjadi aspirasi masyarakat secara merata.

2. Pengembangan etos kerja harus dilaksanakan dalam konteks pendidikan dan pelatihan manajemen dalam arti luas untuk menghasilan keterampilan organisasi yang bermutu tinggi bagi setiap anak bangsa.
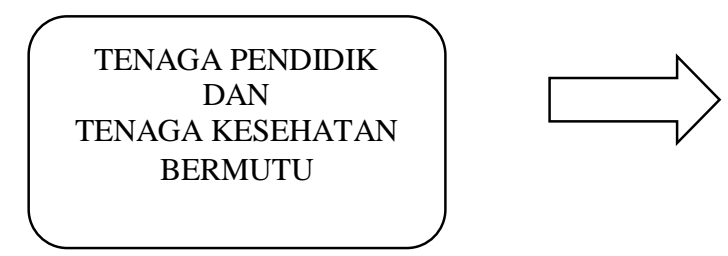

AKAN

MENGHASILKAN SDM

YANG BERKUALITAS

Artinya: untuk meningkatkan mutu tenaga pendidik dan tenaga kesehatan = bagaimana meningkatkan SDM yang berkualitas.

Beberapa hal yang harus dicermati:

1. Apa kriteria tenaga pendidik yang dianggap mampu menghasilkan SDM yang berkualitas?

2. Apakah perlu ditetapkan level pendidikan dan kadar mutu tenaga pendidik sesuai dengan spesifikasi daerah untuk menentukan cara yang tepat meningkatkan mutunya?

3. Apakah perlu pemetaan daerah untuk menentukan skala prioritas dalam upaya meningkatkan mutu tenaga pendidik?

4. Harus disadari masyarakat Indonesia semakin dihinggapi kultur-kultur kemalasan (laziness culture), ketidakpedulian (careless culture) dan ingin cepat berhasil tanpa susah payah (shortcut mentality).

\section{PENUTUP}

Dari gambaran di atas menjadi tugas tenaga pendidik untuk dapat merubah pola pikir mereka. Ini mesti bisa kita lakukan andai kata tenaga pendidik itu berjiwa kebangsaan dan berdaya juang tinggi. Tenaga pendidik yang diharapkan adalah tenaga pendidik bermental pejuang yang mampu membentuk anak didik yang merdeka, berfikir, berkepribadian (be, trusted, honesty) beretos kerja, pandai dan terampil. Untuk itu, konsep pembangunan negara kepulauan diarahkan pada:

1. Mewujudkan Indonesia menjadi negara kepulauan yang mandiri, maju, kuat, berbasiskan kepentingan nasional.

2. Menumbuhkan wawasan bahari bagi masyarakat dan pemerintah agar pembangunan Indonesia berorientasi kelautan. 
3. Meningkatkan kapasitas sumber daya manusia yang berwawasan kelautan melalui pengembangan ilmu pengetahuan dan teknologi kelautan.

4. Mengelola wilayah laut nasional untuk mempertahankan kedaulatan dan kemakmuran.

Membangun ekonomi kelautan secara terpadu dan mengoptimalkan pemanfaatan sumber kekayaan laut secara berkelanjutan.

\section{DAFTAR RUJUKAN}

Kumpulan hasil gagasan ilmiah dalam Paradigma Baru Pembangunan di Forum Konsolidasi Pimpinan Pemerintah Daerah, Angkatan V Lembaga Ketahanan Nasional tahun 2011. 